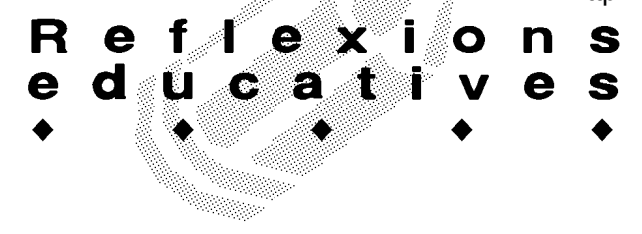

\title{
L'ORDINADOR A L'AULA
}

\author{
Jordi Llabrés Bordoy. Àrea de Personalitat, Avaluació i Tractament Psicològic. \\ Universitat de les Illes Balears
}

Fa quinze anys ningú no dubtava de la importància de les tecnologies de la informació i la comunicació (TIC) en l'àmbit educatiu. En aquell temps no s'usaven les TIC a les aules, però els motius de no fer-ho eren molt clars. Hi havia pocs ordinadors a les escoles i els que hi havia no eren capaços de fer anar el nou programari multimèdia. Aquells programes necessitaven coses tan poc habituals en la majoria d'ordinadors de llavors com ara una tarja de so i uns altaveus.

Els ordinadors a les escoles no eren a les aules, sinó a les "aules d'informàtica", uns llocs on els més grans hi anaven a "aprendre informàtica" i els més petits a jugar amb els programes educatius. En aquells anys també es van fer intents de posar algun ordinador dins les aules, però varen ser experiències aïllades (BARTOLOMÉ, 1999).

A dia d'avui les TIC segueixen sense formar part de la realitat quotidiana dels centres educatius, i ara l'excusa no pot ser només la manca d'ordinadors. Per què no s'usen les TIC a les aules? Per què s'haurien d'utilitzar? Com s'hauria de fer? L'objectiu d'aquestes línies és reflexionar, des d'una perspectiva pràctica, sobre les possibles respostes a aquestes preguntes.

\section{S'haurien d'usar les TIC a les aules?}

Sí. Sembla que en això no hi ha dubtes. Segons l'informe de la Comissió Europea (2006) sobre l'ús de les TIC a les escoles d'Europa, la majoria de professorat d'Espanya considera que les TIC haurien de formar part del procés d'ensenyament. Els avantatges de les TIC són molts. Poden servir com a suport a les classes "tradicionals", poden obrir l'aula a la resta del món i poden millorar el rendiment acadèmic de l'alumnat (GÜLBAHAR, 2006). També poden "millorar l'escriptura de l'alumne, l'aprenentatge col-laboratiu, l'aplicació de determinades estratègies d'aprenentatge, la comunicació amb el professorat, les relacions amb la comunitat i l'aprenentatge en general" (WHITEHEAD, JENSEN i BOSCHEE, 2003).

N'hi ha més (LLABRÉS, 2000). El nivell d'interactivitat que poden oferir els ordinadors pot millorar la motivació i l'atenció de l'alumnat. La multimèdia pot oferir oportunitats de pràctica en situacions realistes, de manera que l'incentiu per practicar és major (WISSIK,
1996). A més a més, quan els ordinadors són utilitzats per petits grups d'alumnes o en parelles (una pràctica molt habitual a les escoles) poden facilitar la integració dels infants que necessitin ajuda en aquest sentit (QUINTANA, BO, FONOLL i SALA, 1998).

Els ordinadors poden oferir instrucció individualitzada i poden donar les ajudes o les instruccions les vegades que l'aprenent vulgui perquè no es cansen mai (BORNAS, SERVERA i LLABRÉS, 1997). El control de la instrucció es deixa a l'alumne, que pot avançar al seu propi ritme. La possibilitat d'estructurar la informació de manera no lineal permet que l'aprenent revisi el material après anteriorment, que practiqui totes les vegades que siguin necessàries, i en el cas dels programes multimèdia, que triï el format de la informació: escoltar la pronunciació d'una paraula, veure el que significa a través de fotografies, observar un gràfic amb l'anàlisi estructural d'aquella paraula (LEWIS, 1998).

Finalment, la possibilitat que tenen els ordinadors d'informar instantàniament sobre el resultat de l'execució de l'alumne supera amb escreix el feedback que el mestre pot donar normalment dins una aula (l'alumne no està sol a l'aula, i haurà d'esperar que el mestre tingui temps per avaluar la seva feina). A més a més, l'ordinador sempre corregeix de la manera en què va ser programat, i ser consistent en la correcció millora l'aprenentatge.

Lògicament els ordinadors no substituiran mai el mestre, però poden alliberar-lo de les tasques més repetitives.

En altres paraules: "Els ordinadors poden ser bons amics. No s'enfaden quan comets un error. Esperen pacientment quan intentes contestar una pregunta o entendre un problema. Et deixen corregir els teus errors fàcilment. Els ordinadors poden ser divertits!" (CUMMINGS i FISHER, 1991).

Es podrien anar llistant els estudis que han anat demostrant que la utilització de les TIC a les aules millora el procés d'ensenyament-aprenentatge, però és que, a més a més, com assenyala Area (2005), quan pràcticament havíem aconseguit eradicar l'analfabetisme "tradicional" n'ha aparegut un altre que serà igualment limitador: l'analfabetisme digital. És completament necessari que les escoles s'adaptin a la societat de la informació actual. Els infants i els adolescents d'avui han crescut 


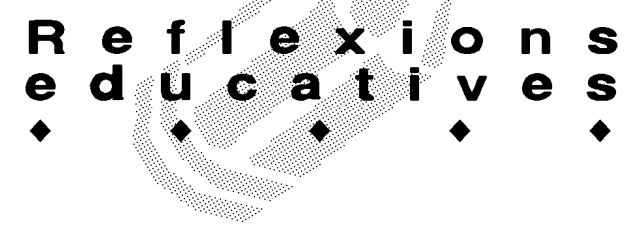

amb el Google, el Flickr, el YouTube, l'eMule, el Messenger i el MySpace. Com ha dit recentment Jordi Adell (2006), l'alumnat és "versió 2.0" mentre que l'escola encara és "versió 0.9 " (les versions 0 són versions beta, inacabades). Els infants i els adolescents processen la informació d'una forma diferent dels adults perquè ells han utilitzat milers d'hores de tecnologia (sobretot fora de l'escola) i mitjans diferents dels que vam utilitzar nosaltres quan érem joves. No és possible dir que ens posarem demà a integrar les TIC a les aules, perquè els alumnes no esperaran ningú i cada cop serà major el decalatge entre ells i nosaltres.

\section{Per què no s'usen les TIC a les aules?}

Segons la Comissió Europea (2006), per respondre a la pregunta haurem d'avaluar fonamentalment tres variables: la competència del professorat en l'ús de les TIC, la seva motivació per utilitzar-les i l'accés que hi tenen.

Avui la manca d'ordinadors a les escoles no pot ser excusa. Dins del programa "Internet en el Aula", entre 2005 i 2008, el govern espanyol dedicarà 453,5 milions d'euros a millorar encara més l'equipament de les escoles. Però clar, tenir molts d'ordinadors no ho és tot. El professorat que va participar en l'enquesta de la Comissió Europea no es queixava tant del nombre d'ordinadors com del seu manteniment i dels continguts educatius d'aquests ordinadors. Els responsables polítics sembla que donen molta importància a les TIC, però alguns creuen que fomentar el seu ús és emplenar les escoles de màquines $\mathrm{i}$ que els infants vagin fent les "fitxes electròniques prefabricades" que acompanyen els llibres de text, però sense tocar gaire l'ordinador, no sigui cosa que el rompin $\mathrm{o}$, pitjor encara, que inventin un virus informàtic.

En definitiva, i en referència a una de les tres variables esmentades, el fet que hi hagi molts ordinadors en una escola no suposa tenir-hi major accés. Què passaria si totes les pissarres d'un centre es posessin en una sola aula? Això és el que se sol fer amb els ordinadors. Si ningú esborrés la pissarra i si ningú reposés el guix, la pissarra no s'utilitzaria. Els ordinadors, com qualsevol altra eina, necessiten un cert manteniment, de manera que estigui disponible quan es necessiti. Per altra banda, els ordinadors no serveixen per a res si no se sap què es pot fer amb ells.

La segona de les variables a tenir en compte és la competència del docent. S'han invertit molts recursos en formació, però sembla que no ha estat de gaire qualitat. Es fan cursos de Linux, d'OpenOffice i, com a molt, de JClic, però ningú sembla saber què s'ha de fer amb tot això (LLABRÉS, 2006). Com s'apliquen les coses que ens ensenyen als cursets d'ofimàtica o d'in- ternet a la pràctica quotidiana? Realment, sembla molt difícil quan la formació rebuda no és adequada. Alguns docents es fan enrere perquè pensen que mai no arribaran a ser capaços d'aprendre a fer anar una eina tan potent. Creuen, erròniament, que és molt complicat elaborar qualsevol tipus de material educatiu amb les TIC, i com que les consideren alienes al currículum decideixen "no perdre més el temps". Per què perdre el temps amb les TIC si fins ara tot s'ha pogut ensenyar i aprendre amb la pissarra i els llibres? Quin temps em quedarà per impartir la meva assignatura després de fer servir els ordinadors?

Lògicament, integrar les TIC en el currículum requereix, almenys en un primer moment, una inversió de temps i ganes, però no es tracta d'afegir sinó de fer les coses d'una altra manera. D'una manera que s'ha demostrat més efectiva per aprendre quan s'utilitza bé.

Però al final el problema és la manca de motivació del professorat. De cop i volta, les seves escoles s'han emplenat de màquines, els han fet cursets d'ofimàtica, els han donat programari que no acaba de servir exactament per a allò que ells voldrien, ningú no es preocupa de mantenir operatives les màquines que han posat $a$ l'escola i quan les volen fer servir no funcionen. Però ningú no els ha explicat què es pot fer amb aquelles màquines. Ningú no els ha dit que les coses que han fet fins ara amb els seus alumnes les podran seguir fent, però ara millor $\mathrm{i}$ amb menys esforç. Tampoc no els han dit que ara poden inventar noves formes d'ensenyar perquè les eines han canviat.

\section{Com utilitzar les TIC a les aules?}

S'ha escrit molt sobre els possibles usos educatius de les TIC (Area, 2002, 2005), però poques vegades es recullen exemples clars i concrets sobre aquestes possibilitats. No es pot ser exhaustiu en aquesta tasca perquè les possibilitats són moltes, però potser algun dels exemples que s'enumeren a continuació, com diu Rosalía Romero (2006), constitueix la petita empenta que cal de vegades perquè un mestre comenci a utilitzar les TIC en la seva pràctica docent.

Wissick (1996) considera que les TIC a les aules es podrien utilitzar de tres formes diferents: com a eina de presentació, com a tutor en una fase d'aprenentatge i com a eina de creació en una fase de recerca.

\section{Eines de presentació}

Com a eines de presentació, les TIC poden millorar l'atenció i la implicació dels alumnes. Quan s'ensenya un concepte nou en una aula d'infantil o de primària, es procura mostrar diferents objectes, paraules, sons i imat$\mathrm{ges}$, relacionats $\mathrm{amb}$ aquell concepte. La multimèdia per- 


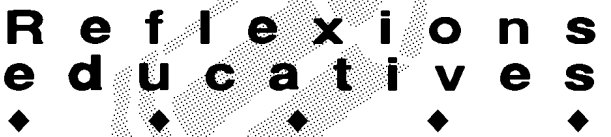

met fer el mateix d'una forma més senzilla i efectiva.

Un exemple clar d'això és el zoo de las letras. Es tracta d'un multimèdia educatiu realitzat per un grup de mestres del CEIP Fuente Nueva de Màlaga. Tal i com expliquen les autores a la seva pàgina web, la idea de fer aquest material educatiu va sortir de la necessitat de complementar el mètode de lecto-escriptura que utilitzaven en aquell moment. En el zoo de las letras, un grup d'animals ensenyen a llegir i a escriure a dos infants. $\mathrm{Hi}$ ha el ratolí Ramón, la vaca Violeta i l'hipopòtam Hipo, que sempre està afònic (perquè la $h$ és muda). Cada lletra té un personatge i cada personatge, una cançó i un conte. Els infants de 3 i 4 anys es familiaritzen amb les lletres a través dels personatges, i amb els de 5 anys es treballa la lecto-escriptura. El zoo s'utilitza de forma integrada en el currículum. Quan els infants dibuixen, en lloc de posar qualsevol música escolten les cançons del zoo; quan els mestres preparen activitats de treball individual (les 'fitxes'), utilitzen els personatges del zoo, i quan surt un conill en un conte, tots recorden el conill Cosme del zoo de las letras. Aquest multimèdia no és un programa professional. Els dibuixos són "fets a mà" $i$ les animacions van "a salts", però això fa el programa més proper als infants, els quals prefereixen la interacció a l'enlluernament dels efectes especials. Segons les autores, el $95 \%$ dels infants de 5 anys llegeixen passat el primer trimestre i han adquirit la correcta direccionalitat de les grafies donat que el projecte inclou unes animacions que indiquen la direcció de cada lletra.

\section{Eines d'entrenament}

En segon lloc, en una fase d'aprenentatge, l'ordinador pot fer de tutor donant les instruccions per fer la tasca i avaluant l'execució de l'alumne. De fet, aquest és l'ús més freqüent del programari educatiu. Els ordinadors són consistents a l'hora de donar les instruccions i d'avaluar l'execució de l'aprenent, i això millora l'aprenentatge. Però el gran avantatge està en el que pot fer el mestre mentre l'ordinador fa les tasques repetitives.

Imaginem que avui el mestre ensenya a sumar.
Explica com es fa a la pissarra, fa un parell d'exemples $\mathrm{i}$ quan creu que la majoria de la classe ho ha entès, demana que comencin a treballar amb el programari de sumes que tenia preparat. Els ordinadors van proposant sumes $\mathrm{i}$ avaluen els resultats que van introduint els alumnes. El mestre va ajudant individualment els que no han entès com es fan les sumes o prepara noves activitats. Els alumnes van treballant cadascú al seu ritme i s'ajuden uns als altres quan a un no li surt.

El problema segurament serà trobar un programari de sumes que faci exactament el que vol el mestre. Per aquest motiu, la millor manera de solucionar la manca de programari educatiu adaptat a les necessitats concretes de la classe és fer-se'l un mateix. Els programes d'autor permeten fer qualsevol tipus de programari amb uns coneixements bàsics d'informàtica, sense necessitat de conèixer complexos llenguatges de programació.

En un estudi que realitzàrem en una escola de Palma durant el curs 1998-1999 (LLABRÉS, 2000) vam programar un multimèdia amb un programa d'autor anomenat MM ToolBook per intentar millorar el rendiment acadèmic d'un grup d'infants de tercer de primària en les assignatures de llenguatge i matemàtiques. Les activitats incloses al multimèdia es van extreure directament dels llibres de text dels infants i s'anaven afegint més activitats mentre el tutor anava avançant en el temari. Com que no hi havia ordinadors a les aules, els infants que van participar en l'estudi havien de sortir de la classe per anar a l'aula d'informàtica a treballar amb el programa. D'aquesta manera, les hores de treball a la sala d'informàtica no s'afegien a la docència tradicional, sinó que la substituïen. Al final de l'estudi els infants que havien sortit de classe per anar a treballar amb els ordinadors presentaren el mateix rendiment en matemàtiques i llenguatge que els seus companys. Significa això que els ordinadors poden substituir els mestres? És clar que no. El que significa és que les hores de treball repetitiu que sempre s'han de fer per aprendre (per aprendre a sumar s'han de fer moltes sumes) podrien estar "tutoritzades" per ordinadors sempre que el pro-

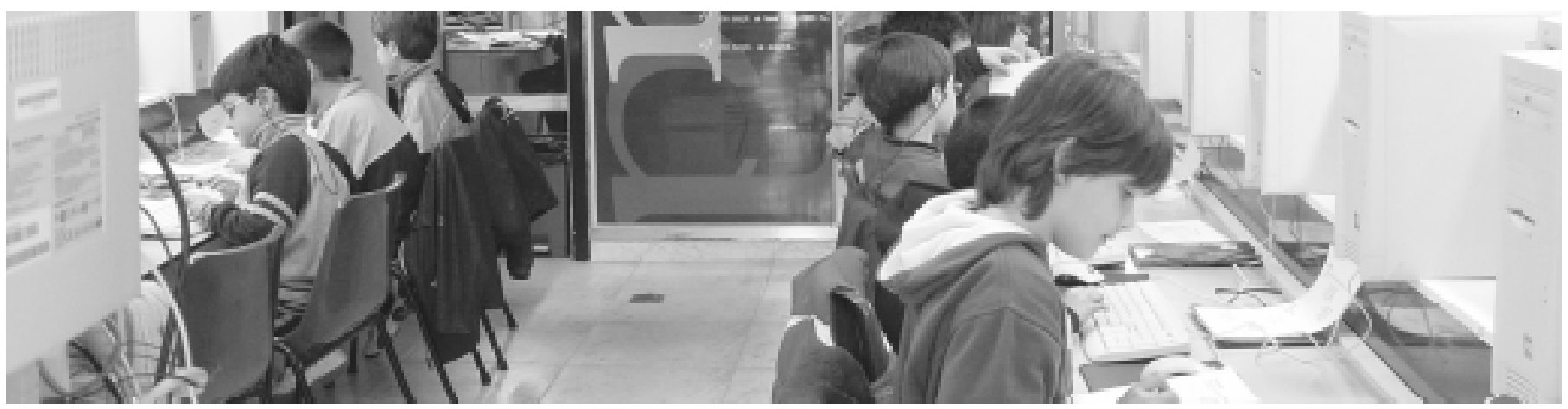




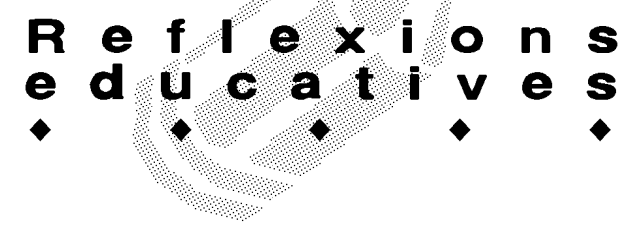

gramari fos adequat. Com deia abans, durant aquestes hores, els mestres es podrien dedicar a coses molt més interessants que a preparar i corregir sumes, com ara ajudar els infants amb més problemes o dissenyar activitats docents engrescadores o fer avaluacions individualitzades dels seus alumnes.

\section{Eines de creació}

Finalment, en una fase de recerca, les TIC es poden fer servir com a eina de creació. Els alumnes poden utilitzar els ordinadors per realitzar els seus propis projectes multimèdia i així assegurar la generalització de l'aprenentatge. Aquesta és probablement la funció educativa més atractiva que poden tenir les TIC, tot i que també és la menys posada en pràctica.

El grup de telemàtica educativa del Moviment Educatiu del Maresme (2005) ja fa uns anys que, entenent les TIC com a eina d'aprenentatge i no com un aprenentatge en si mateix, han posat en marxa, entre d'altres, el projecte dels hipercontes. Un hiperconte és un conte interactiu que, a partir d'una determinada proposta de partida, es va construint de mica en mica entre els participants (alumnes de primària de diferents escoles). Els objectius del projecte no són només aprendre a fer anar el programari que permet construir el conte i publicar coses a internet, sinó, entre d'altres, comprendre l'estructura narrativa, usar correctament els signes de puntuació, saber cercar i després resumir informació a internet, sentir-se part del grup i valorar el treball cooperatiu.

El CEIP San Pedro de Alcántara ha triat els podcasts per compartir la feina que fan a educació primària. Un podcast no és res més que àudio sincronitzat $a m b$ imatges, tot empaquetat en un format que permeti ser descarregat d'internet amb facilitat. Els alumnes de San Pedro (http://www.juntadeandalucia.es/averroes/ sanpedro/sp/Podcast/Podcast.html) han publicat al seu web els darrers podcasts que han creat ells mateixos, enregistrant les seves veus amb un ordinador, escanejant els seus dibuixos, fent les fotos amb la càmera digital $i$ integrant-t'ho tot en un programa de fàcil utilització: el GarageBand. Un dels seus darrers podcasts explica el concepte de la velocitat a través d'imatges dels mateixos alumnes a classe d'educació física, comentades amb locucions realitzades per ells mateixos. El treball que hi ha darrere dels pocs minuts que dura el podcast és impressionant: col-laborar en la selecció de les millors fotografies, assaigs de locució per enregistrar correctament el so, recollida de la informació més rellevant sobre el concepte que es vol explicar, etc.

Els weblogs, blogs, blocs o bitàcoles (sistemes per publicar continguts a internet de forma molt senzilla que permeten la interacció amb el lector) poden ser també grans recursos educatius. Jové, Jubany i Vilà (2006) enumeren alguns possibles usos a primària: diari col.lectiu de la classe, on s'enregistren els esdeveniments del dia; diari individual dels alumnes sobre el que passa a l'escola per contrastar punts de vista; jocs col-lectius sobre algun tema a base de preguntes i respostes; elaboració de relats col-lectius; debats sobre temes d'actualitat; preparació de les assemblees o les tutories, etc. AI CEIP Miguel Servet editen un periòdic (en paper i al web) utilitzant aquesta tecnologia. La descripció que fa Miguel Calvo (2005) de com es va redactar una de les notícies del 20 d'octubre de 2004 em sembla un exemple magnífic del potencial de les TIC com a eines de creació. Resulta que quan els alumnes que aquell dia eren els "caps de redacció" estaven a punt de començar a redactar la notícia del dia, va entrar un enorme insecte dins l'aula. Allò sí que era una notícia i l'alumna encarregada del material va anar corrents a cercar la càmera digital. Van fer fotos de l'insecte, en triaren una i l'editaren amb un programa de retoc d'imatges per poder-la penjar al web. Mentrestant, la discussió sobre el tipus d'insecte que era no s'acabava, i es van haver de fer algunes consultes a l'amic Google. Aquell dia es va decidir que era un "insecte pal". Amb un processador de textos es va redactar la notícia i es va penjar al web. L'endemà, quan ja havien deixat en llibertat l'insecte i després de veure com un ocell se'l menjava, es van trobar proves gràfiques a internet que demostraren que en realitat es tractava d'una mantis i no d'un "insecte pal". El 21 d'octubre es van publicar les fotografies que mostraven les diferències entre els "insectes pal" i les mantis (també es van publicar les excuses a Luis, el qual sempre havia mantingut que es tractava d'una mantis).

El darrer exemple de les TIC com a eines de creació s'ha reservat a l'educació infantil i a M. Teresa Santiago (també coneguda com "chimpum"). Els infants del taller d'imatge d'aquesta mestra han estrenat la seva darrera pel-lícula, un documental sobre el canvi climàtic titulat "¡Cambia!', el gener de 2007. Però el 2004 es publicava al web del "Proyecto Grimm" un article explicant com un grup de 37 alumnes de 4 anys havien realitzat una pel-lícula d'animació titulada "Cardito Caracol". Aquell curs els infants havien començat a treballar aquest conte i decidiren convertir-lo en pel-lícula. Es dibuixaren els personatges. Entre tots es triaren els millors dibuixos i es retallaren. Es va dibuixar el decorat en un paper continu i es va preparar, amb l'ajuda de tots, el guió tècnic de la pel-lícula (l'story-board). Ara s'havia de fer la filmació movent els personatges retallats per damunt el decorat. La càmera de vídeo estava sempre muntada al trípode, els retalls col-locats sobre el decorat $i$, durant mesos, els infants que anaven acabant les feines de 


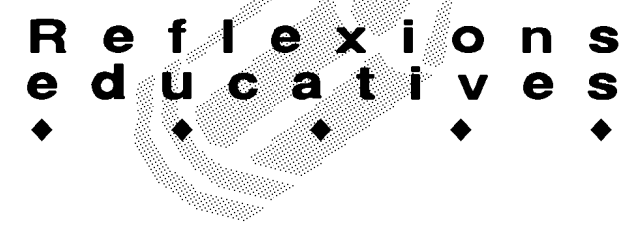

cada dia anaven passant pel set de filmació per ajudar a fer la pel-lícula. Després, també entre tots, es va triar la banda sonora entre les audicions musicals habituals d'aquell any. Triaren "La Flauta Mágica" de Mozart. Finalment es va provar d'enregistrar els diàlegs, però els infants de 4 anys no eren capaços de recordar-los i hagueren de demanar ajuda als alumnes de primària. El muntatge, lògicament, l'hagueren de fer les mestres. La pel-lícula es va estrenar el 12 de juny de 2004.

\section{Què significa integrar les TIC a l'aula?}

Els anteriors són magnífics exemples d'integració de les TIC. Probablement no podrem dir que les TIC s'han integrat en les aules fins que no s'utilitzin de la mateixa manera que s'utilitzen les altres eines educatives. Per què no s'envia els infants a jugar amb la pissarra i en canvi se'ls diu que fins que no acabin la feina no podran anar a jugar al racó dels ordinadors? Per què no s'aprèn a "fer anar" els llibres i es fa una assignatura per aprendre a fer anar un ordinador? Per què no s'aprèn a llegir amb llibres de mecànica, i en canvi s'aprèn a fer anar els ordinadors amb programes com ara el Word? Per què es permet als infants embrutarse amb els retoladors i no es permet ni que canviïn les icones de l'escriptori?

Integrar les TIC no significa invertir grans recursos en màquines o en formació del professorat. No significa, tot i que estaria molt bé, que totes les aules siguin com les de l'experiència pionera de l'escola d'Ariño (BLESA, 2005), on cada infant té un ordinador portàtil a classe amb connexió sense fils a internet. Significa tenir clar que si avui no és possible ensenyar utilitzant plomes i tinters, demà no ho serà sense l'ordinador (no d'aquí a un temps no, demà).

\section{Referències bibliogràfiques}

ADELL, J. Riesgos y posibilidades de las TICs en educación. Ponència a la 'XXI Semana Monográfica de la Educación', novembre 2006. Disponible a: http://www.xtec.net/ cbarba1/ Articles/adell.pdf

AREA, M. Problemas y retos educativos ante las tecnologías digitales en la sociedad de la información. "Quaderns Digitals» (2002). Disponible a: http://webpages.ull.es/users/ manarea/documento15.htm

AREA, M. La escuela y la sociedad de la información. A «Nuevas tecnologías, globalización y migraciones». Edit. OCTAEDRO, Barcelona, 2005. Pàg. 13-54.

BARTOLOMÉ, A. El ordenador en el aula. Proyecto Grimm. (1999) Disponible a: http://proyectogrimm.net/ index.php?cmd=cont articulo\&id $=148$

BLESA, J.A. La escuela digital: una experiencia pionera de la escuela de Ariño (Teruel). "Comunicación y Pedagogía», 202 (2005) 67-70.
BORNAS, X., SERVERA, M., i LLABRÉS, J. Preventing impulsivity in the classroom: how computers can help teachers. "Computers in the Schools», 13 (1997) 27-40.

CALVO, M. Nuevos cuadernos, otros tinteros. "Comunicación y Pedagogía», 202 (2005) 45-48.

CUMMINGS, R. W., i FISHER, G. L. The school survival guide for kids with LD (learning differences). Minneapolis, MN: Free Spirit Publishing. 1991. Pàg. 21.

COMISSIÓ EUROPEA. (EUROPEAN COMISSION). Benchmarking Access and Use of ICT in European Schools 2006. Disponible a: http://ec.europa.eu/information_society/ newsroom/cf/itemlongdetail.cfm?item id=2888

GRUP DE TELEMÀTICA EDUCATIVA DEL MOVIMENT EDUCATIU DEL MARESME. Los hipercuentos: una experiencia telemática educativa. "Comunicación y Pedagogía», 202 (2005) 71-76.

GÜLBAHAR, Y. Technology planning: A roadmap to succesful technology integration in schools. "Computers \& Education», en premsa (2006).

JOVÉ, O., JUBANY, J. i VILÀ, N. Bitácoras en Primaria o las nuevas formas de comunicación. "Comunicación y Pedagogía», 209 (2006) 9-14.

LEWIS, R. B. Assistive technology and learning disabilities: Today's realities and tomorrow's promises. «Journal of Learning Disabilities», 31 (1998) 16-26.

LLABRÉS, J. Intervenció assistida per ordinador en infants de primària amb baix rendiment acadèmic. Tesis doctoral no publicada, 2000. Disponible a: http://www.tdx.cesca.es/TDX0308105-101927/

LLABRÉS, J. ¿Por qué no se usan las tecnologías de la información y la comunicación en las aulas? Proyecto Grimm, 2006. Disponible a: http://www.proyectogrimm.net/index. php?cmd=cont_articulo\&id $=403$

QUINTANA, J., BO, I., FONOLL, J. i SALA, M. Efectos colaterales que los alumnos con necesidades educativas especiales obtienen del uso de ordenadores: un modelo de integración socio-educativa. «Comunicación y Pedagogía», 150 (1998) 27-29.

ROMERO, R. Profesores creadores de medios (NTIC). “Comunicación y Pedagogía», 209 (2006) 65-69.

WHITEHEAD, B.M., JENSEN, D.F.N i BOSCHEE, F. Planning for technology: A guide for school administrators, technology coordinators, and curriculum leaders. Ed. Corwin Press, USA. 2003. Pàg. 10-12.

WISSIK, C. (1996). Multimedia: Enhancing instruction for students with learning disabilities. «Journal of Learning Disabilities», 29 (1996) 494-503.

\section{Adreces d'internet}

Zoo de letras. CEIP Fuente Nueva de Màlaga. Disponible a: http://www.juntadeandalucia.es/averroes/intervideo/Zooletras/ GUIA DIDACTICA/INTRODUCCION.html

Periòdics digitals. Disponibles a: http://periodicos. walqa.com/

Proyecto Grimm. Pel.lícula d'animació "Cardito Caracol". Disponible a: http://www.proyectogrimm.net/index.php? cmd=cont_articulo\&id=188 